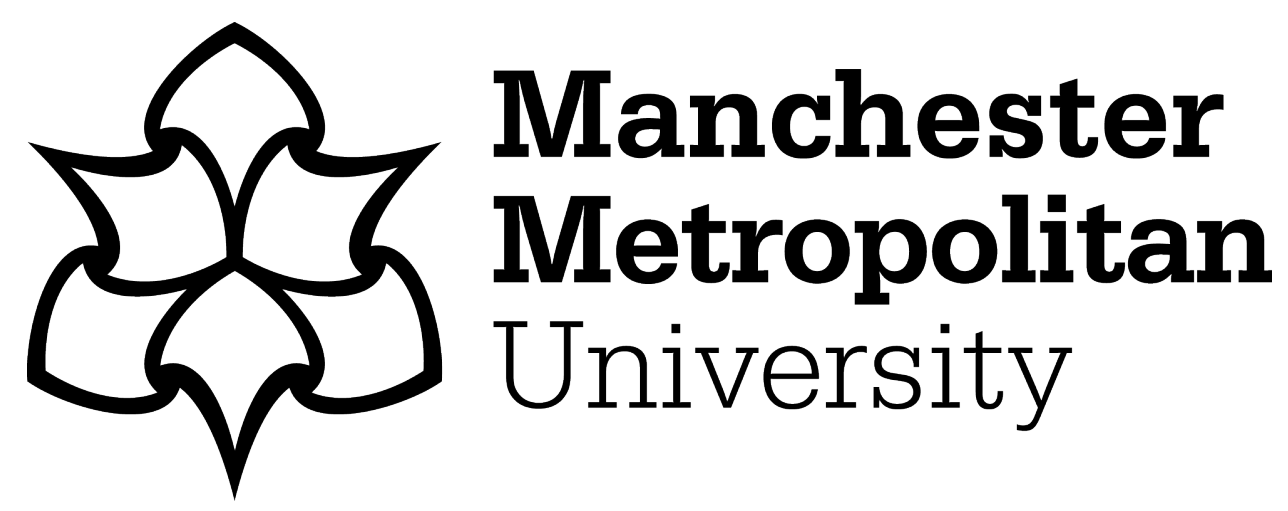

Brown, Tony (2007) The art of mathematics: bedding down for a new era. Educational Philosophy and Theory, 39 (7). pp. 755-765. ISSN 0013-1857

Downloaded from: https://e-space.mmu.ac.uk/40374/

Version: Accepted Version

Publisher: Taylor \& Francis (Routledge)

DOI: https://doi.org/10.1111/j.1469-5812.2007.00318.x

Please cite the published version 


\title{
The Art of Mathematics: Bedding down for a new era
}

\author{
TONY BROWN \\ Manchester Metropolitan University
}

This paper was inspired by a session I attended at a Psychology of Mathematics Education conference in Honolulu. Nathalie Sinclair (2003) was presenting some of her work on how we might see mathematics in terms of its aesthetic qualities. Various contributors at the session commented on the qualities of different mathematical proofs using such criteria as "economic", "neat" and "elegant". I found the session especially intriguing and engaging as it was targeted at examining how such qualities might become more prominent in our teaching of children.

Nevertheless, I found myself adopting a fairly guarded attitude, as so often, when mathematics is presented as being pleasing aesthetically, it draws attention to qualities missed by so many people. As a result, I found myself wrong footed in that my main motive as a mathematical educator is to find ways of the subject reaching a broader audience and in an environment where mathematics' prominent position on the school curriculum is underwritten by its perceived utility. Sinclair's session appeared more like an art appreciation class and in art education rather different sorts of motivations are offered in defending art's more marginal position on the curriculum. As a result I started to explore the ways in which mathematics and art educators sell their wares differently to children in schools and to their sponsors. And in doing this I began to question how a notion of aesthetic might function as a motivation in creating and evaluating mathematical or artistic objects. Questions arose such as: What analogies might we productively draw between mathematics and art education? How might we see the promotion of aesthetic appreciation as a motivating factor in mathematics? How might we define the relation between mathematical and artistic objects and human subjects? These questions led to more general concerns with how humans relate to mathematics, and, in stepping back from that, to how we might understand the notion of relation in this context. Ultimately, this paper addresses the question of how we might understand the shifting borders defining the space that houses mathematical thinking and learning as we begin a new century where "mathematical" and "pedagogy" have become increasingly contentious terms. I commence by considering how the human subject directs their thinking towards such concerns and float some options as to how this subject might be understood. By considering how this thinking might be understood in relation to an art object I prepare the ground for drawing analogies with the perception of mathematical objects. Art, however, is not about the simple production of objects. Nor is it just about aesthetics. Rather its performative aspects draw in the response that it activates such that this very response becomes part of its own domain. Thus we consider how mathematics and its learning might be seen as elements of performance shaped by societal conceptions of the task it serves. After considering some examples of mathematical performance I conclude with identifying some immediate implications for interpreting our present 
practice in mathematics teaching and a longer term prognosis for how mathematics might evolve in tandem with newer conceptions of the human subject and how they learn.

\section{Physical Objects, Human Subjects}

In the voluminous works of Sigmund Freud a central concept was that of ego. Nevertheless, Freud's work developed over some fifty years and the way in which Freud deployed such key terms evolved through successive meanings. The notion of ego has provoked some especially contentious debate. Without doubt Freud was ambivalent on this issue and some of his later work left it unresolved. In his earlier work (e.g. Freud, 1923) Freud understood the ego as a biological entity and his paper established a cartographic representation of the human mind comprising ego, id and super ego. In this conception of the ego, psychoanalytical treatment was understood in terms of developing the ego to increasingly occupy the territory governed by the id. This was announced by the slogan: Where the id was the ego shall be. This version of the ego was embraced by the US ego psychology school and has gained an image of seeing psychoanalytic therapy in terms of calming the ego to be more conformist. At various other points, including some of his very latest work, the ego was understood very differently. It was understood as a relational entity produced through the subject's identification with other people and the world around. It was this version of the ego that has been developed by Freud's belligerent disciple Jacques Lacan. For Lacan the ego is an inauthentic agency derived from a delusional stance in which the human subject has an image of his or her self. As such the ego is something to be challenged. Therapy is targeted instead at locating the truth of the patient's desire. That is, treatment is seen in terms of understanding how the unconscious functions in conditioning the patient's expressed demands. Lacan suggests that when the analysand says "I", the analyst should be mistrustful. That is, the image of self that is portrayed needs to be inspected to discover how it is a distortion of the desires that are being activated. Grosz (1989) offers a helpful summary of the two egos.

In the first model we would find a fairly familiar depiction of an individual human subject existing as a standalone biological entity who casts his or her attention over mathematical or artistic objects that also standalone. The psychological basis of so much mathematics education research would fall under this banner as encapsulated in the tradition of the Psychology of Mathematics Education organisation. The alternative is not a sociological model as may be supposed. Or rather, it is not sociological in that we work from a holistic conception of society that shapes individuals within it. Lacan's relational ego is a result of fantasy. This fantasy does not have negative connotations. Rather, our understanding of reality is seen as being structured through such fantasies. Fantasies might be seen as the filters through which we inspect reality, a reality that in a sense cannot be perceived directly, and in some other senses is not there at all except through its manifestation in the fantasies of individuals. In this cartography we would not have a standalone biological human confronting an independent object. For analytical purposes the space would be carved up differently. There would be no overarching perspective from an independent arbiter. The analysis would be centred on the human subject's supposed relation to the object and the world he or she crafts around it. 
Let us take some examples from art to illustrate potential understanding of this relationally produced subject. In his book, "Post-Modernism, or the Cultural Logic of Late Capitalism", Jameson (1971, pp. 6-10) proposes an interesting distinction between Modernism and Post-Modernism. He associates hermeneutical depth interpretation with the former and the textuality of post-structuralism with the latter. He illustrates this by contrasting two paintings described briefly here. I have discussed this more elsewhere (Brown, 2001).

\section{"A Pair of Boots" by van Gogh}

Jameson suggests that van Gogh's painting of a pair of peasant's boots gives rise to the possibility of various interpretations. He offers the magnificence of the bucolic landscapes we might normally associate with the paintings of van Gogh or alternatively, the stark peasant lifestyle suggested by such clothing. Either view can be developed as an account of what the painting might be seen as evoking.

\section{"Diamond Dust Shoes" by Warhol}

Warhol's effort, a dark, sparse, shadowy affair depicting contemporary shoes that may have been produced with the help of an X-Ray machine or a photocopier seems to defy any such generation of stories. It seems to be all in the surface - it begins and ends with the painting.

These two works, a century and a half a century old respectively, were both challenges to their respective publics. They were not about beauty. They redefined draughtsmanship or aesthetics in any previously known sense. They were both seemingly targeted at activating something in the viewer beyond mere appreciation. But one might suggest that we have moved on from here and the domain of art criticism has entered very different territory. Let us take two newsworthy British examples from the last five years.

\section{Tracy Emin's Bed}

Tracy Emin caused one of the most notorious controversies in British public life with her entry for the prestigious Turner Prize. The exhibit comprised her bed. The bed, allegedly, had been transported in to the gallery "as it was" with unmade sheets and various items unmentionable in polite society.

\section{Holiday in Spain}

A group of art students from Leeds were given a grant to enable them to produce their degree show. They took some photos purportedly to depict how they had spent the money. The photos showed the group in Spain enjoying a holiday and they organized a reception committee to greet them as they arrived at Leeds-Bradford airport. Soon after the British tabloid press had a field day berating lazy students for wasting taxpayer's money, while the more serious papers published articles discussing the meaning of art. The students then revealed that the whole thing had been a carefully staged event and that the photos were in fact a fabrication taken at a beach a few miles away in cold conditions. They had not spent any of the money. Their degree show comprised the "original" photos, the newspaper headlines, a performance element at the airport and an account of how they had produced the fabrication. 
Both works presumably were designed to be provocative. In some sense these two works take post-modernism one step further than Jameson's account. That is, the art is not so much in the surface, as outside of it. The meaning of the work of art is defined by the reaction to it. For Emin's piece the question seemed to be about why this is seen as art. How come it is being considered for a major award? What can we say about the way in which this work activated public reaction? How does it transgress public conceptions of the personal? This very transgressive attitude, asserting its own awkwardness of fit into what counts as art, activated the response that became part of the art object's specific evolution in public conception and of art generally in its now expanded form. Emin's piece became a British cultural icon of the nineties and she has established herself as a major artist, part of a re-defined British art establishment. The Tate Gallery has bought a selection of her major works to be put in a room dedicated to her work. Meanwhile, the Holiday in Spain, as a degree show, had its public response and media feedback built into its very physical presence. Public or, at least, media reaction was something that the work sought to alert us to in a new way. Here, the relational space between human and object is not usefully seen as a space between an object and biologically defined ego. The relational ego is rather more helpful in coming to terms with such art in that the works are about the way in which you relate to them and what that assumed relationship tells you about yourself and your connection to the world of which you are part. They were extremely successful in activating a multi-layered debate with wide participation on the question of what is art? Arguably, they achieved this more than any other British artist in recent years apart from Emin. Would the staging of such a large-scale public event be possible to address the question of what is mathematics?

\section{Mathematics (Education) As Performance}

Mathematics must surely join art in seeing its domain as transcending singular notions of beauty. Mathematics, like art, can teach us about ourselves, but not necessarily through didactic means. That is, the student may be allowed to learn their own lesson rather than the one supposed by their teacher or some other authority about what constitutes beauty or correctness. Further, Deborah Britzman (2003) has shown us how the lessons of school can take many years to settle and take us by surprise when we least expect it. The content of school learning as defined by the teacher has a very different cartography to the assimilation of it made by students. Elsewhere, I have argued that we have to see the boundaries of mathematical activity more broadly (Brown and McNamara, 2005). This point will be developed a little in the final section. What follows are brief accounts of four mathematical events; a public lecture on advanced mathematics, the publication of a popular book discussing mathematical physics, a public mathematics examination for aspiring primary teachers and a controversy surrounding the publication of some school examination statistics. These accounts each situate mathematics in a public domain and are chosen to exemplify cultural manifestations of mathematics that perhaps offer some opportunity to better understand the public image of mathematics. This provides a route towards understanding how mathematics, inspected more locally, might enable us to learn a little about ourselves through the way in which mathematics is used and 
understood. The descriptions will be followed by an evaluation of them in terms of how they predicate conceptions of mathematics and people responding to mathematics as a cultural phenomenon.

\section{A Public Lecture in Mathematics}

The mathematician Caroline Series gave a number of public lectures in New Zealand. The publicity for the events featured intricate and colourful images reminiscent, to a novice at least, of the widely known Mandelbroit images of fractals. Mumford, Series and Wright (2002) provide an account of these images. The lecture in Hamilton was widely attended. It would be unusual for many mathematicians to command such attention. The mathematics presented was probably inaccessible to many of the people present including myself, yet the images were sufficient for me to warm to the associated symbols. It was as if the beauty of the images invested the symbols with a meaning that could not be deduced through the symbols themselves. To what extent might we apprehend this like the supposed depth of van Gogh's painting insofar as the meaning of his painting is understood as being a profound association between the symbolic presentation and the hidden meaning? Yet for so many, certainly for me, it appeared to be in the surface, as with Warhol's shoes, attractive images that stand in the way of access to any depth behind. In some sense this is familiar territory as regards assumed links between mathematics and art. Geometric images such as Islamic patterns are common in classrooms as learning (e.g. Sinclair, 2001; Sharp, 2001). Here art and mathematics are seen as intersecting in images or objects for the physically independent human to behold. This appears to be in the same genre as Sinclair's work with children. It certainly had the same attraction for me except that I understood the mathematics in Sinclair's session and that I could envisage the possibilities for children across a broader spectrum. More recently, Sinclair (2004) has supplied some intriguing hints at how such aesthetic concerns can link to affective experience of mathematics.

\section{Stephen Hawking's "The Brief History of Time"}

Stephen Hawking's book was a best seller (Hawking, 1988). The cultural theorist Slavoj Zizek (1997, p. 173), a contemporary successor to Lacan, offers a somewhat unsympathetic reading of this success. He asks "Would his ruminations about the fate of the universe, his endeavour to 'read the mind of God', remain so attractive to the public if it were not for the fact that they emanate from the crippled, paralysed body, communicating with the world only through the feeble movement of one finger and speaking with a machine generated impersonal voice?" Zizek contends that Hawking's iconic status results from this very disability in that Hawking stands in for the general state of subjectivity today (p. 135). Can one imagine any other mathematician standing in for his performance on Radiohead's OK Computer, often voted the most popular rock album of recent years? One imagines millions of e-connected, socially dysfunctional adolescents wriggling their mouse fingers in ecstasy as they empathise with Hawking's plea to be heard from his depleted state. It would make doing mathematics homework seem ultimately worthwhile. And indeed, these people include some of mathematics education's best clients. As a phenomenon it is not the meaning of what Hawking says but the mode of performance and how the performative aspects of his delivery speak for 
mathematics and physics and the relationship they are perceived as having with the world by a broader public. Zizek (2001, p. 213) argues that Hawking is an exponent of what Brockman (1996) has called The Third Culture. Here, a "new type of public intellectual ... who, in the eyes of the wider public, stands more and more for the one "supposed to know', trusted to reveal the keys to the great secrets which concern us all." Zizek (op cit, p. 215-216) goes on to suggest "as they are clarifying the ultimate enigmas ... (they) silently pass over the burning questions which actually occupy centre stage in current politico-ideological debates". Thus such a public image of mathematics is an image problem for those enticing young students in to the area. Furthermore, such singular conceptions of beauty and totality do not only support a Third Culture, they have also been known to lead to the Third Reich.

\section{The British Numeracy Skills Test For Primary Teachers}

The image of mathematics being a private activity of a lone student grappling with symbols has surely been disrupted in certain contexts such as the UK where mathematics has become a rule governed activity externally defined by government agencies that check that prospective teachers share the same understanding. My colleague Olwen McNamara describes the following scene, reported in Brown and McNamara (2005, pp. 43-45), set at one of the largest Initial Teacher Training providers in the United Kingdom.

The cast: 830 trainee teachers.

The audience: (absent but "overwhelmingly" supportive) the Great British public who "never forget a good teacher" (Teachers Training Agency, 1999).

The stage: 34 rooms across the Campus. The largest held 120, the smallest 16 . There were special rooms set aside for dyslexic students, non-native English speakers and latecomers.

The script: included oral/mental and written components and was devised by the United Kingdom Teachers Training Agency and naturally remained undisclosed to the cast until the performance; but was known to focus upon their "wider context of their professional role as a teacher".

The rehearsals: practice scripts were available in abundance and managed centrally through "web-based resources", although hard copies and help lines were also available.

The directors: worked solidly for days prior to the performance enlisting back stage support, planning, producing room lists, counting out scripts (lack of sufficient spares available made contingency arrangements exceedingly tricky); preparing individualised instruction packs for the stage managers/runners; and (to reduce commotion and disruption) stopping builders from building, gardeners from cutting lawns, and beer lorries from delivering.

The stage-managers: 40 invigilators and 20 runners (provided with mobile phones due to the size of the campus) were drawn from amongst the academic and administrative staff.

The stagehands: a House Services team worked tirelessly for days setting out the requisite amount of chairs and tables in the 34 rooms and ensuring security and access.

The props: audio equipment was provided for each room to deliver the mental/oral test, prerecorded on audiotape. Above and beyond what was already available, this alone cost $£ 1000$. Backup calculators, pens, rulers, paper cups and water were also supplied in great numbers. 
The pre-performance briefing: planned, according to the director, with "military precision" took place in Lecture Theatre A at 10.15am.

The performance: almost faultless - the stage managers reported only one audiocassette to be mal-functional. Only 2 of the 830 cast were late and a further one reported with a slight malaise at the beginning of the performance (most probably a case of stage fright). Less impressive, however, was that one in ten of the cast forgot their registration number and/or their photographic identification (a problem in the offing!)

The post-performance debriefing: took place again in Lecture Theatre A where slightly less "military precision" was apparent due to the unexpected presence of about 80 of the cast under guard until such time as they could be reunited with their scripts and registration number and/or be identified by an official. Scripts were cross-checked against attendance; missing scripts checked against the absentee list; unused scripts, as instructed, returned forthwith.

This highly staged event was very much about mathematics in the eyes of the students and of the government setting the test. The event tells us a lot about the country, its mode of governance, its sense of how things get done. Underlying this social nexus is a very specific interpretation of mathematics linked to some specific assumptions about the mathematical knowledge teachers must demonstrate before they can begin earning a salary as a primary teacher.

\section{The (im)possibility of perfection in children's achievement}

Recent education policy for secondary pupils in New Zealand has been based around an assessment regime designed to include all pupils, such that everyone can achieve. Nevertheless, recent controversy led to the dismissal of a prominent school principal after $100 \%$ success had been declared for her pupils. It transpired that children had been assigned a wide variety of tasks to enable them to make this perfect score an achievable and defensible reality. Others, however, felt that the principal's tactics had been a blatant attempt to massage life to create statistics.

The story was headline news in New Zealand for a number of weeks, focusing on the assessment strategies used, the dispute that led to the principal's dismissal and the subsequent student protests. This public performance of statistical arguments and their underlying premises exposed how they are used and abused to shape our world. The mathematical dimension could not have been extracted to become independent of this highly interpretive environment.

\section{Concluding Remarks}

If we were to be guided by Freud's first conception of the ego we might wonder how we would now operate on the ego towards transforming it, perhaps strengthening it, through some sort of educative process. The mathematics education research community centre this understanding on the work of Piaget. The principal departure from this has been towards the earlier work of Vygotsky, who offered a more socially oriented conception of the learner. The relational ego of Freud, however, displays certain delusional aspects that would prevent an easy alignment with Vygotsky. It is not something that one would wish 
to strengthen, in oneself or others. Rather, one is more concerned with exploring the ego to see how it functions, how it reveals the person's desires. We would not be interested in getting the ego to mirror some model of perfection in an external object. Rather, the task is to learn about oneself through your understanding of your relationship to the stimulus offered.

Art education itself has been shaped around somewhat outmoded or, at least, limited conceptions of art (Atkinson, 2002). Contemporary art has long since moved on from notions of art objects being admired by independent observers. Similarly, practitioners in mathematics education, insofar as they see themselves sharing some of art education's aspirations, (such as attending to aesthetic qualities, self expression, learning about oneself) are potentially locked into a similar time warp as regards how we should understand mathematical objects. In mathematics education there is much benefit to be gained from understanding the discipline's aesthetic qualities and in finding ways to enable our students to share these pleasures. This paper was motivated by the need for this whilst trying to understand these qualities in a broader way. There are risks however in underwriting those pleasures as though they provide access to a more beautiful world beyond. The works of mathematicians and physicists like Caroline Series and Stephen Hawking paint a picture of mathematics that offers few markers for school children looking for ways to tackle real life problems. No more than classic art providing anchorage to contemporary manifestations of art. The fringe artist, the struggling student and the Sunday painter are potentially all just as helpful in provoking critical reflection. The aspiration to a grand theory anchored around world leaders can neglect more immediate tasks and map out the territory in ways that might seem distorted within certain readings. It is unhelpful, I believe, to demand that school mathematics needs to be underwritten by its supposed connections to such advanced mathematics. Mathematics, seen more broadly and more locally, provides models of varying scales that enable us to inspect the world, for its beauty and for its deformities. School mathematics needs to have a brief that enables more possibilities in enabling children to learn about themselves and learning to express themselves. The children need to understand how the mathematics they learn is shaped around life and how life is shaped around mathematics.

The description of the Numeracy Skills Test paints a picture of a country in which former aspirations that mathematics be created in classrooms by teachers and children are replaced by a notion of mathematics externally defined by the government seeking to ensure that its ideological take on mathematics is embraced by all. This seems to be about mass ego management predicated on Freud's first conception of ego. The policy is seemingly designed to have a mechanical effect on the brain of each individual through an instrumentally defined route. Perhaps the social effects (Who am I? How do I fit in?) are served better by the second conception of ego. By seeing the boundaries of mathematics extending into its social performance we enable more possibilities but to support this we need a conception of human subjects that accepts this intrinsic relationality in their very formation.

Finally, for the New Zealand principal, her very attempts to deliver the ideal held up by the government as supposedly achievable, made the system itself, to which she was subscribing, all too faithfully, appear to lack credibility. Zizek (e.g. 1989) argues that regimes require a cynical distance among their populace for their ideologies to work. Statistics no longer remains a measure of life if life is forced to fit the required image. 
The mathematical measure demonstrating perfection or the guidelines advising how this could be achieved, showed that the conception of perfection was not altogether perfect. Models crack and the world cracks but we can learn from these events but not necessarily by holding them against notions of perfection or universality that generally have had a poor track record.

Such issues have immediate consequences for the interpretation of our everyday teaching in schools. Pedagogical strategies and the demonstrable skills of children are often seen as subordinate to the mathematical conceptions they seek to engender. Perhaps, however, such a view should be contested since the teaching devices of school mathematics need also to be understood as constructed and implicit components of the mathematical ideas we wish our students to encounter. The commodifications of mathematics are not all bad. The performative aspects of mathematical activity need to be understood as well as the mathematics supposedly underlying this. Elsewhere I provide an example of children attending to these aspects (Brown, 2001, pp. 101-102). This does not preclude the possibility that the mathematical thinking can be "sufficiently abstracted to be removable from its practice" (Barton, 2004, p. 23). Yet the social and linguistic conditioning of mathematics is necessarily a crucial aspect of the discipline being addressed in school and vocational courses. Proficiency with concretisations is integral to the broader proficiency of moving between concrete and abstract domains, as are the social dynamics that surrounds it, proficiencies that lies at the heart of mathematical endeavours (at least in schools). Indeed, one might suggest that for many students and many teachers proficiency in specific concretisations forms the core and key motivation of activity pursued within the classroom.

Meanwhile we can also be attentive to longer-term trends. Art has traditionally provided apparatus for (wo)mankind to inspect itself. Mathematics also has reflective and reflexive functions worthy of further development and attention, that help humans to affirm images of themselves and also to disrupt these images for further growth. These are encountered through objects, rituals and other events. Learning mathematics is intricately tied up with the architecture of emotional and intellectual space. But societal relations define the very contents of individual brains and perhaps individuals cannot see themselves outside of those parameters (Althusser, 1971; Butler, 1997). Yet those are the parameters that govern and explain the individual's actions. Mathematics can be part of the kit bag of resources that might enable us to better understand how those parameters work.

\section{References}

Althusser, L. (1971) Ideology and ideological state apparatuses, in: Lenin and Philosophy and other Essays. (London, New Left Books).

Atkinson, D. (2002) Art in Education: Identity and Practice. (Dordrecht, Kluwer).

Barton, B. (2004) Mathematics and mathematical practices: where to draw the line. For the Learning of Mathematics, 24(1): 22-24.

Britzman, D. (2003) After Education, (Albany, State University of New York Press).

Brockman, J. (1996) The Third Culture. (New York, Simon and Shuster).

Brown, T. (2001) Mathematics Education and Language: Interpreting Hermeneutics and Poststructuralism. (Dordrecht, Kluwer). 
Brown, T. and McNamara, O. (2005) New Teacher Identity and Regulative Government: The Discursive Formation of Primary Mathematics Teacher Education. (New York, Springer).

Butler, J. (1997) The Psychic Life of Power. (Stanford, Stanford University Press).

Freud (1923) The ego and the id, in: S. Freud (1991) The Essentials of Psycho-analysis. (London, Penguin).

Grosz, E. (1989) Jacques Lacan: a Feminist Introduction. (London, Routledge).

Hawking, S. (1988) A Brief History of Time. (New York, Bantam Books).

Jameson, F. (1971) Postmodernism or the Cultural Logic of Late Capitalism. (Durham USA, Duke University Press).

Mumford, D., Series, C. and Wright, D. (2002) Indra's pearls: The vision of Felix Klein. (Cambridge, Cambridge University Press).

Sharp, J. (2002) Pictures inspired by Theo van Doesburg, For the Learning of Mathematics, 22(3):18-19.

Sinclair, N. (2002) Re-constructing a painting with geometric eyes, For the Learning of Mathematics, 22(3): 19-22.

Sinclair, N. (2003) Aesthetic values in mathematics: A value oriented epistemology. In Pateman, N. Dougherty, B. and Zillox, J. (Eds.) Proceedings of the Joint Meeting of PME and PMENA. Honolulu: CRDG College of Education, University of Hawai'i.

Sinclair, N. (2004) The roles of the aesthetic in mathematical inquiry, Mathematics Thinking and Learning, 6(3): 261-284.

Teachers Training Agency (1999) National Skills Tests: a guide for trainee teachers. (London, Teachers Training Agency).

Zizek, S (1989) The Sublime Object of Ideology. (London, Verso).

Zizek, S. (1997) The Plague of Fantasies. (London, Verso).

Zizek, S. (2001) Did Somebody Say Totalitarianism? Five interventions in the (mis) use of a notion. (London, Verso). 